RESEARCH PAPER RP1485

Part of Journal of Research of the National Bureau of Standards, Volume 29, July 1942

\title{
NOTE ON FLEXURAL FATIGUE OF TEXTILES
}

\author{
By Herbert F. Schiefer and Paul M. Boyland
}

\section{ABSTRACT}

Results are given which indicate that the ability of a textile fabric to withstand repeated flexing depends upon the structure of the fabric, the position and structure of the yarn in the fabric, and the kind of fiber from which the fabric is made.

\section{CONTENTS}

I. Introduction $\ldots \ldots \ldots \ldots$

II. Testing procedure

III. Results _

\section{INTRODUCTION}

Textile fabrics are complex structures composed of many fibers arranged in more or less definite patterns according to the distribution of the fibers in the yarns and of the yarns in the fabric. The ability of a fabric to withstand repeated flexing depends not onlyon the properties of the fibers but also on the structure of the yarn and of the fabric. This dependence was brought out in some experiments on the folding endurance of certain fabrics, the results of which are discussed briefly in this note.

\section{TESTING PROCEDURE}

Specimens of a fabric were ravelled to $15 \mathrm{~mm}$. in width. Some of these specimens were tested for breaking strength and elongation. The remaining specimens were flexed in an M.I.T. folding tester ${ }^{1}$ under a tension of $1.5 \mathrm{~kg}$. The specimens were folded through $135^{\circ}$, alternately toward one face and then toward the other at the rate of 200 double folds per minute. The nominal radius of curvature of the edges of the jaws is $0.38 \mathrm{~mm}$. The flexing tests were discontinued after a certain predetermined number of double folds, and the flexed specimens were then tested for breaking strength and elongation. The percentage decreases in breaking strength and in elongation of the flexed specimens, based upon the original breaking strength and elongation, were computed. Some of the flexed specimens were photographed before they were tested for strength to show the position of the failures of the fibers and of the yarns in relation to the fabric structure. For this purpose the specimen was folded through $180^{\circ}$ and placed between two microscope glass slides with the edge of the folded specimen coinciding with the line of folding in the flexing test.

\section{RESULTS}

Repeatedly flexed specimens are shown in figures 1 and 2 . It is clear from these photographs that the fibers which have failed occur

\footnotetext{
${ }^{1}$ L. W. Snyder and F. T. Carson, A study of the M.I.T. paper folding tester, Paper Trade J. 96, TS276
} (June 1, 1933). 
in alternate yarns. The positions of the failures of fibers in alternate yarns are attributable to the fabric structure and can be explained with the schematic drawings of a fabric in figure 3 . The top view of the fabric is given at $a$. Sectional views through $B B$ and $C C$, respectively, are represented by $b$ and $c ; b^{\prime}$ and $c^{\prime}$ represent these same sections when the fabric is folded upon itself, $B$ to $B$ and $C$ to $C$ with the upper surface inside; $b^{\prime \prime}$ and $c^{\prime \prime}$ represent the sections when the fabric is folded with the lower surface inside. It can be seen from these figures that the radius of curvature of the yarns designated $B$ is very much larger than in $b^{\prime}$ than in $b^{\prime \prime}$. The opposite is true for the yarns designated $C$. The bending stress due to folding a given yarn will increase with the increase in the curvature of the fold. The maximum stress of the $B$ yarns is obtained when the fabric is folded as in $\mathrm{b}^{\prime \prime}$, and the maximum stress of the $C$ yarns is obtained when the fabric is folded as in $c^{\prime}$. If these foldings are repeated, as in flexural-fatigue tests, it is apparent that the $B$ yarns will begin to fail (rupture) at $x$, and the $C$ yarns will begin to fail at $y$. The $x$ failures will occur in alternate yarns on one side of the fabric, and $y$ failures will occur in the other set of alternate yarns on the other side. This is what is shown in figures 1 and 2 , and the position of the failures of the fibers in the alternate yarns of the fabrics is entirely attributable to the differences in stress and strain which arise from the fabric structure. Specimen $A$ of figure 1, which was inserted in the folding tester at a slight angle, is of special interest. It shows that the failures of the warp yarns change from one set of alternate yarns to the other set at the position marked $P$. This position corresponds to the place where the bending of the warp yarns over one filling yarn changes to bending over an adjacent filling yarn.

It is also clear in the photographs in figures 1 and 2 that some of the fibers have been broken by repeated folding. The percentage decrease in breaking strength and in elongation due to folding is given in table 1. It is seen to depend upon the number of double folds and upon the kind of fiber. The large percentage decrease for the fabrics made from acetate rayon, fortisan, and silk compared to no decrease for the fabrics made from viscose rayon, nylon, and cotton is outstanding. This difference cannot be attributed to a change in weave or fabric structure. It is more likely that structural differences of the yarns and of the fibers in a yarn account for this large difference.

The short cotton fibers in a yarn are freer to move relative to one another when the fabric is flexed. Hence the fibers would be strained less when the yarn is bent to a given radius of curvature. This would result in an increase in folding endurance of cotton fabrics.

As the freedom of movement of the fibers in a yarn relative to each other is restricted the yarn approaches the properties of a homogeneous beam and the extreme fiber strains for bending to a radius $R$ increases from the value $r_{1} / R$, where $r_{1}$ is the radius of the fiber, to $r_{2} / R$, where $r_{2}$ is the radius of the yarn. The extreme fiber stresses would increase correspondingly. Similarly, restriction of the movement of the yarns in a fabric relative to each other would increase the extreme fiber stresses corresponding to a given curvature of the fold. The extreme fiber strain for bending a fabric would approach the value of $r_{3} / R$, where $r_{3}$ is one-half the thickness of the fabric. 

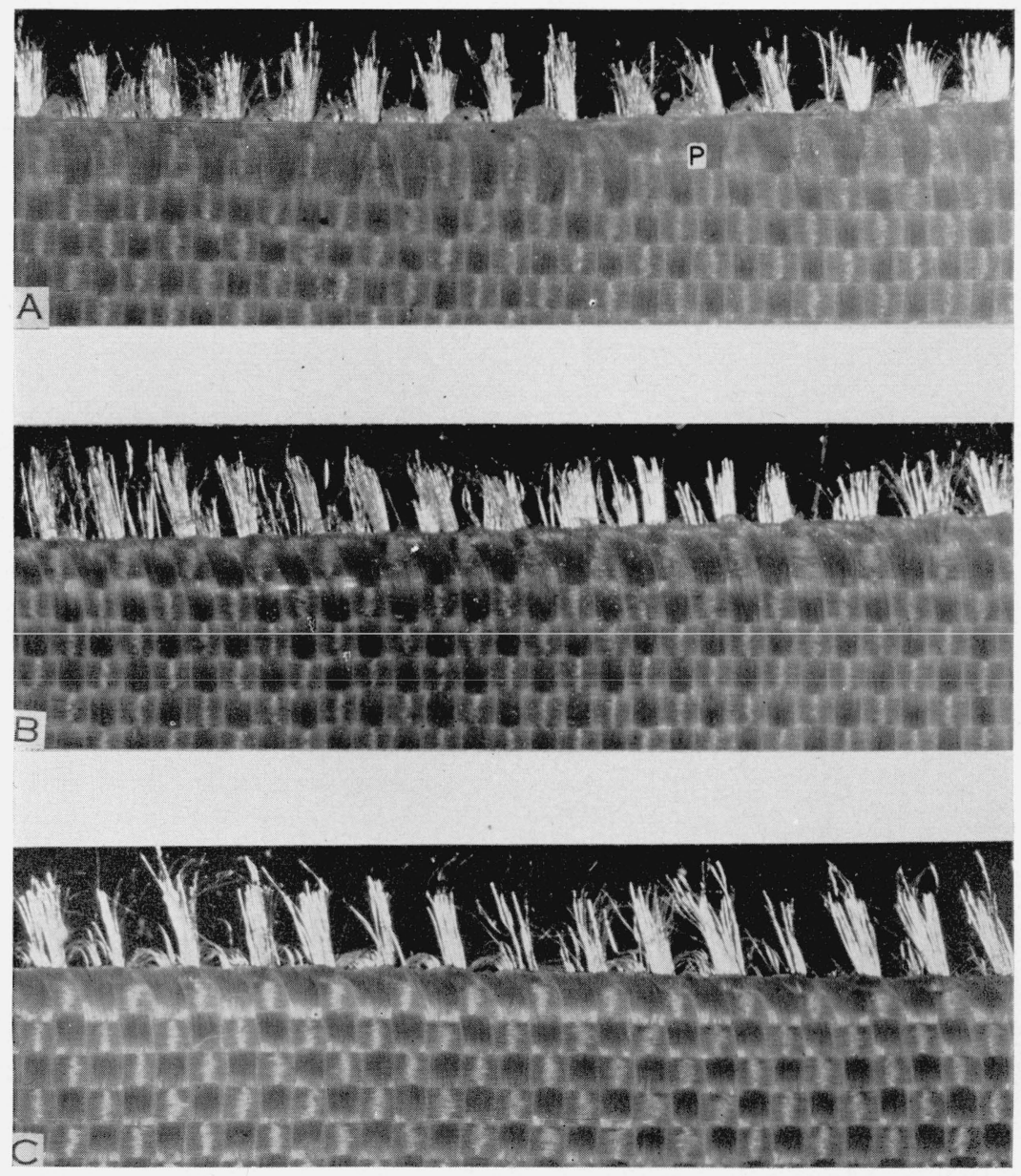

FIGURE 1.-Test specimens showing that the failures of fibers caused by flexural fatigue occur in alternate yarns.

A, Fortisan, warp, 10,000 double folds; B, Fortisan, warp, 8,000 double folds; C, Fortisan, filling, 5,000 double folds. Magnification $\times 14$. 

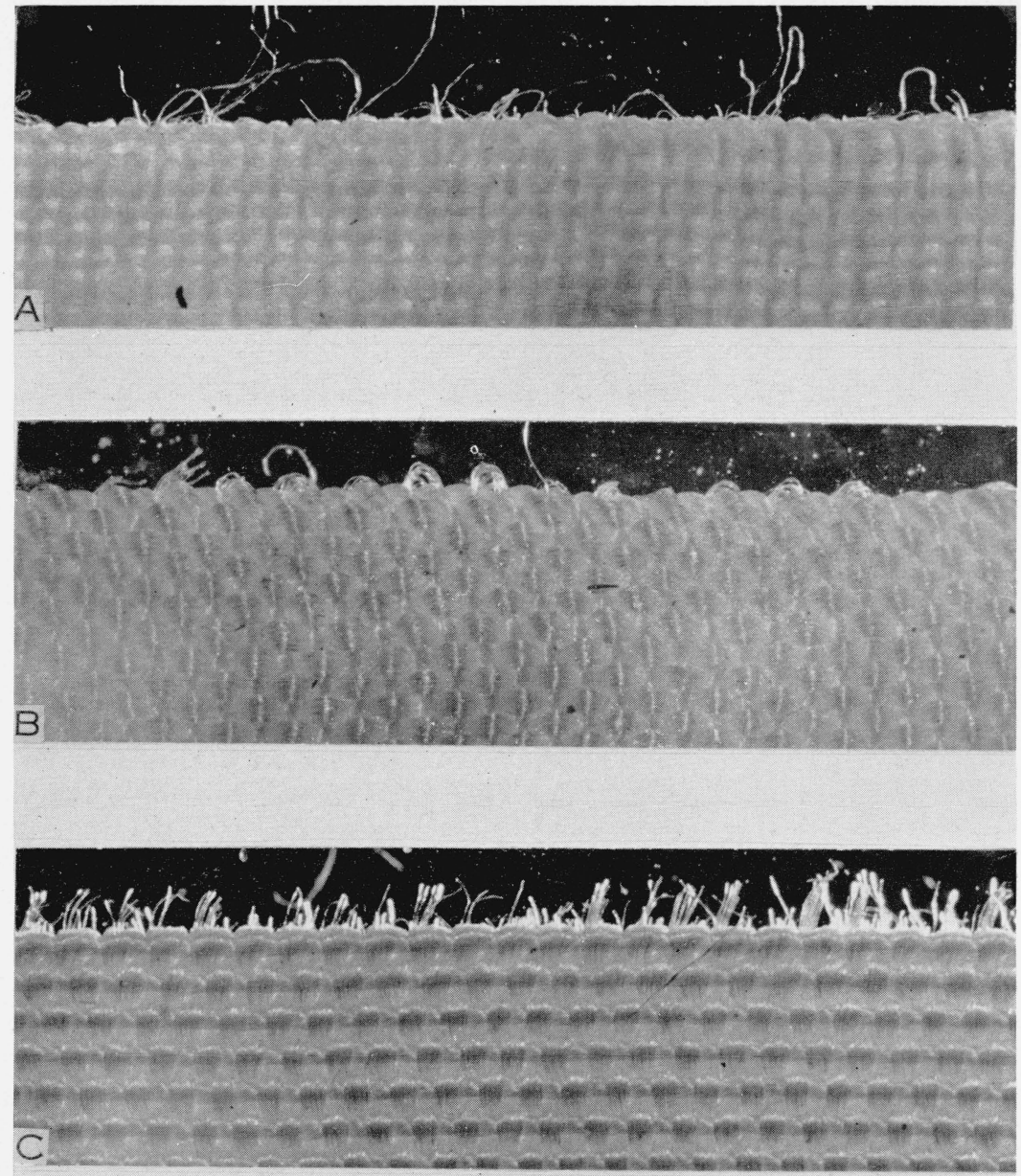

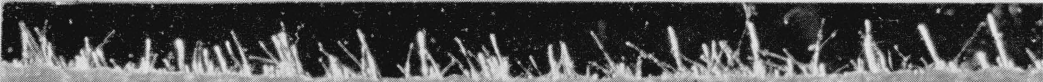

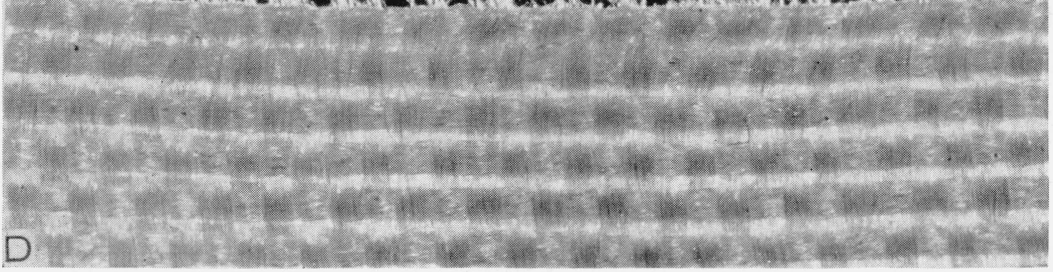

Figure 2.-Test specimens showing that the failures of fibers caused by flexural fatigue occur in alternate yarns.

A, cotton, filling, 10,000 double folds; B, viscose rayon, filling, 10,000 double folds; C, acetate rayon, warp, 1,500 double folds; $D$, silk, filling, 10,000 double folds. Magnification $\times 14$. 


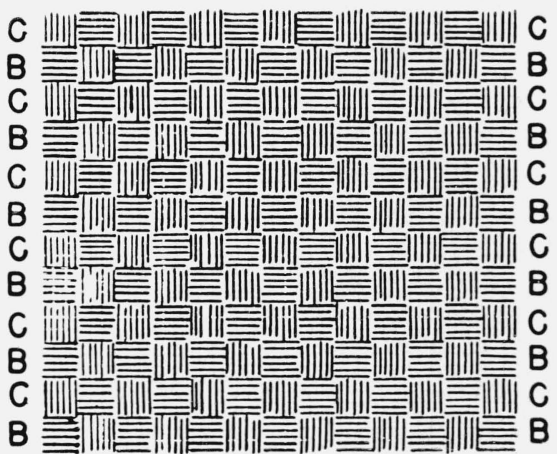

a

$$
\text { b' }
$$
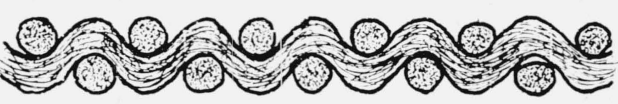

b

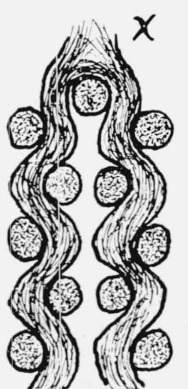

$c^{\prime}$
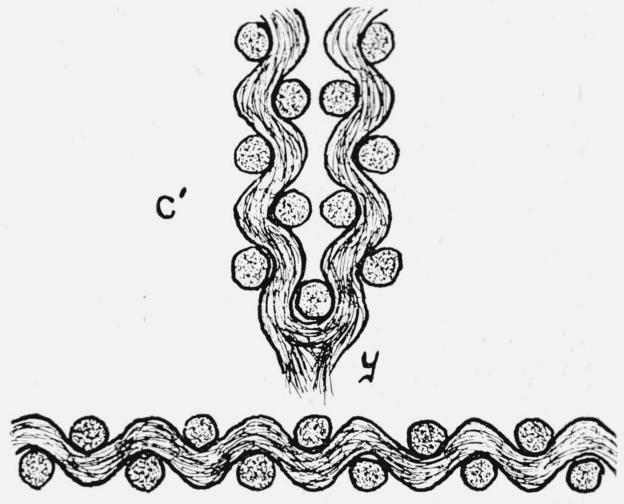

C

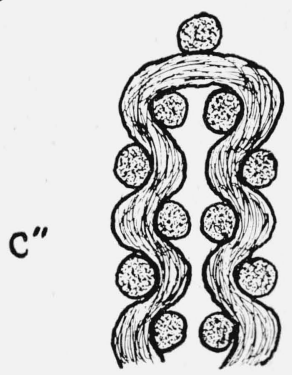

FIGURE 3-Schematic drawing of a plain woven fabric and sectional views showing position of alternate yarns during a flexural-fatigue test 
TABLE 1.-Decrease in the breaking strength and elongation of fabrics by repeated folding

\begin{tabular}{|c|c|c|c|}
\hline \multirow[b]{2}{*}{ Material } & \multirow{2}{*}{$\begin{array}{l}\text { Number of } \\
\text { double folds }\end{array}$} & \multicolumn{2}{|c|}{ Decrease in - } \\
\hline & & $\begin{array}{l}\text { Breaking } \\
\text { strength }\end{array}$ & $\begin{array}{l}\text { Elonga- } \\
\text { tion }\end{array}$ \\
\hline Rayon, acetate.... & 1,000 & Percent & ${ }^{\text {Percent }}{ }_{31}$ \\
\hline & $\begin{array}{l}1,700 \\
2,000\end{array}$ & $\begin{array}{r}56 \\
100\end{array}$ & $\begin{array}{r}59 \\
100\end{array}$ \\
\hline $\begin{array}{l}\text { Fortisan: } \\
\text { Warp }\end{array}$ & 1,000 & 25 & 14 \\
\hline Filling... & $\begin{array}{r}8,000 \\
10,000 \\
1,000\end{array}$ & $\begin{array}{r}63 \\
68 \\
0\end{array}$ & $\begin{array}{r}57 \\
57 \\
0\end{array}$ \\
\hline Silk: & 10,000 & 35 & 30 \\
\hline Filling & $\begin{array}{r}10,000 \\
5,000\end{array}$ & $\begin{array}{l}46 \\
27\end{array}$ & $\begin{array}{l}40 \\
54 \\
36\end{array}$ \\
\hline $\begin{array}{l}\text { Rayon, viscose } \\
\text { Nylon: }\end{array}$ & $\begin{array}{l}10,000 \\
10,000\end{array}$ & $\begin{array}{r}55 \\
0\end{array}$ & \\
\hline & 10,000 & 0 & 0 \\
\hline $\begin{array}{l}\text { Filling } \\
\text { Cotton: } \\
\text { Warp }\end{array}$ & $\begin{array}{l}10,000 \\
10,000\end{array}$ & $\begin{array}{l}0 \\
0\end{array}$ & \\
\hline $\begin{array}{l}\text { Filling } \\
\text { Fortisan: }\end{array}$ & $\begin{array}{l}50,000 \\
10,000\end{array}$ & $\begin{array}{l}0 \\
0\end{array}$ & \\
\hline Warp & $\begin{array}{r}2,000 \\
10,000\end{array}$ & 47 & (a) \\
\hline The & $\begin{array}{r}2,000 \\
10,000\end{array}$ & $\begin{array}{l}25 \\
54\end{array}$ & (a) \\
\hline $\begin{array}{l}\text { Fortisan, rubber-coated: } \\
\text { Warp }\end{array}$ & 2,000 & 45 & (a) \\
\hline Filling & 2,000 & 38 & (a) \\
\hline $\begin{array}{l}\text { Fortisan, neoprene-coated: } \\
\text { Warp }\end{array}$ & $\begin{array}{r}10,000 \\
2,000\end{array}$ & 85 & (a) \\
\hline Filling & $\begin{array}{l}2,000 \\
2,000 \\
5,000\end{array}$ & $\begin{array}{r}100 \\
50 \\
62\end{array}$ & $\begin{array}{l}\left(\begin{array}{l}(x) \\
(\mathrm{a}) \\
(\mathrm{a})\end{array}\right. \\
-\end{array}$ \\
\hline
\end{tabular}

a Elongation was not measured.

It follows that restriction of movement of fibers and of yarns in a fabric should decrease the folding endurance. This effect is shown by the data in table 1 for the rubber and neoprene coatings on a fortisan fabric. The particular neoprene coating greatly increased the stiffness of the fabric, and hence restricted the movement of the fibers and yarns during folding very much more than the rubber coating. The effect of the greater restriction of the movement of the fibers and yarns by the neoprene coating on the folding endurance is clearly indicated.

Similarly, differences in the freedom of movement of the structural units within fibers, which may result from chemical or mechanical treatment of the fibers, would affect the folding endurance of the fibers and also of the yarns and fabrics made from them.

Textile materials are frequently folded to a degree for which the computed value of $r / R$, the extreme fiber strain, exceeds 0.25 . For this value of $r / R$, which corresponds to an elongation of 25 percent, the elastic limit of some textile fibers is exceeded and permanent deformation or creasing results.

Washington, May 8, 1942. 